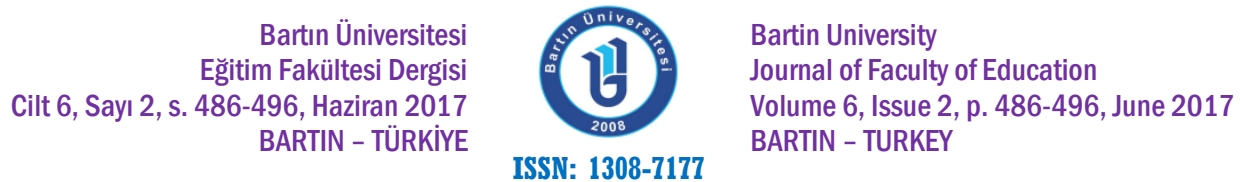

Doi: 10.14686/buefad.308546

\title{
Sosyoloji Eğitim ve Algısı Üzerine Tümcü Bir Arayış Denemesi
}

\author{
Ali ÖZTÜRK, Yrd. Doç. Dr., Bartın Üniversitesi, Edebiyat Fakültesi, imajoloji@gmail.com
}

Öz: Türkiye'de sosyoloji bölümleri çok çeşitli sebeplere bağlı olarak gittikçe artmaktadır. Kuşkusuz bu sadece sosyoloji bölümlerine özgü bir durum değildir. Ancak sosyoloji bölümleri gerek talep edilmeleri bakımından gerekse üstlendiği rol bakımından birtakım ayrıt edici özelliklere sahiptir. Fakat sosyolojinin kendisine yönelen bu talepleri nasıl karşıladığı önemlidir. Nitekim kendisine biçilen rol konusunda yer yer bulanık ve verimsiz bir işlev ürettiği söylenebilir.

Kuşkusuz bu bölümlerin ve disiplinin başardığı birçok şeyi gölgelemeye yönelik bir yargı değildir. Ancak sosyoloji eğitiminin yer yer belirsizleşen rol ve işlevini geliştirmeye ve netleştirmeye ihtiyacımız var. Çünkü sosyolojinin kısmen kendine özgü olarak bireyin temas ettiği birçok şeyi yine kendine özgü sistematiklerle yorumlamayı imkâna bağlayan bir cevheri olduğu da dikkate alındığında bu daha da önem kazanmaktadır.

Bu çalışmada, genelde tüm sosyal bilimlerde, temelde ise sosyolojide bir talebenin talim gördüğü lisans ve lisansüstü eğitimde karşılaştığı birçok teori, yaklaşım, metot, teknik, model, kavram, uygulama alanı, çözüm önerisi, düşünür ve kitaba rağmen, kimi simgesel aparatlar ve bazı öncelenen sorunlar dışında karşılaştığı sorunları büyük ölçüde önceden kazandığı yargı teknikleriyle yorumlamaya devam etmesi açmazını bütünsel bir yaklaşımla masaya yatırıp kimi teklifler getirilmesi hedeflenmektedir.

Anahtar Kelimeler: sosyoloji eğitimi, sosyolojik imgelem, teori, metot, fabrikleştirim.

\section{A Holistic Inquiry into Sociology Education and Its Perception}

Abstract: Sociology Departments are getting arisen as depending on many reasons day by day in Turkey. Indeed this situation is not only valid for sociology but departments of sociology have one kind of the same different properties with regard to demand and their functions. However, it is important how sociology supply with this demand. Thus we can say that sociology has partly created unfertile and vague functions time to time.

Unquestionably, this judgement does not refer to under estimate the many achievements of sociology departments. On the other hand we need to develop and clarify partly seeing the insufficient and misleading role of sociology education today. Because sociology is a discipline that allows us to interpret every stage of life with its own techniques as well as many other roles.

In this study, it is aimed to put some proposals on the table with a holistic approach by means of which to understand and solve the problems. Since it has encountered with the judiciary techniques, that have already been gained in large measure, although there are many theories, approaches, methods, techniques, models, concepts, application areas, solution proposals, thinkers and books, which are basically compared in all social sciences beforehand, then a demanded student of the undergraduate and of the graduate education of sociology departments, except for some symbolic apparatuses and some preliminary problems.

Key Words: sociology education, sociological imaginary, theory, method, fabrication. 


\section{GiRiş}

Sosyolojinin başlıca rollerinden birisi de görebilme ve gördüğünü formüle edebilme yeteneğini kazandırmaktır. Fakat sosyoloji bölümleri bunu kazandırma konusunda kimi sorunlar yaşamaktadır. Sosyoloji talimindeki bu başlıktaki başlıca sorunları genel olarak şu şekilde ifade etmek mümkündür; öncelikle öğrencilerin sorunları ve kavramları gerçeklikle ve kavramların kendi orijinleriyle bağ kurarak anlayamaması ciddi bir açmazıdır. Sosyolojik terim, metot ve yaklaşımlar gerçekliği görmede öğrencilerde yeterince bir değişim meydana getirmiyor. Şayet hassasiyet kesilecek bir gerçeklik varsa bu gerçekliğin de genelde dikte edilmiş mitik bir gerçekli ya da popüler bir idol olarak kıymet bulması ayrıca öneme haiz bir durumdur. Ayrıca öğrencinin ya da akademisyenin gerçekliği sorunsallatırması disiplinin ihtiyaçlarından çok başka saiklere, örneğin ait olduğu gettonun uyarımlarına bağlı olarak gerçekleşmesi daha mümkün olabilmektedir.

Bununla birlikte sosyoloji ve sosyal bilimler öğretisinde arz edilen metodolojik liderliğin çok parçalı ve uzlaşmaz bir hikaye resmettiği de dikkati çekmektedir. İndirgemeci teori öğretisi, popüler, spekülatif ve sansasyonel yargı baskısı, kaotik imgesel yoğunlaşmalar ve teknisyenlik faaliyetleri gibi uzlaşmaz bir yığıımanın da bu süreci iyice bulanıklaştırdığı vakidir. Buna bağlı olarak da öğrencilerin, öğrendikleri ya da aşina oldukları sosyolojik terim, kavram, yaklaşım, metot ve tekniklerin sahici ontolojilerini kavrayarak onu gerek bir hareket noktası olarak kullanmak, gerekse uyumsuzluklarını bizatihi test ederek görebilmek ve geliştirmekten (Barnes, 1995, s. 137) çok uzaktırlar.

İkincisiyse yorum gücüne sahip olma sorunudur. Öğrenciler gördükleri teori, metot ve teknikleri yorumlama enstrümanı olarak kullanmayı düşünmüyorlar. Yeni durumları ya da paralel bir olguyu şayet çalışmamışlarsa sosyolojinin imkanlarıyla yorumlamaktan çok uzak bir performans ile ve dahi daha çok gündelik yaşam refleksleriyle yorumluyorlar. Nitekim "yorum sorusu mu soracaksınız", dendiğinde bile yorum konseptinin ne kadar yanlış anlaşıldığı ortaya çıkıyor. Oysaki yorum, birçok işlevinin yanı sıra, bir sorun hakkında aklına gelini söylemekten daha başka bir şeydir ve birçok boyutu vardır (Yıldırım, 2007, s. 48-49). En basit anlamda yorum, bir sahaya bağlı olarak, o sahanın ihtiyaç duyduğu metotlar, yaklaşımlar, teoriler ve konu ile saha arasında bir bağ kurarak yeterli maddi ve teknik bilgiye dayalı olarak onu nasıl kıymetlendirdiğiyle ilgili bir durumdur.

Üçüncü olarak ise bir sorunu modelleyerek, görmeyi ya da sorunsallaştırmayı tutarlı bir sistematiğe, olgunlaşmış oyun kuralına bağlamayı başaramıyorlar. Yapabildikleri en büyük iş oyuna dair parlak bir replik parlatmaktan öteye geçmiyor, tıpkı bir tamircinin kimsenin bulamadığı bir arızayı bulmakla övündüğü gibi (Öztürk, 2015, s. 113), neredeyse arabanın icadından daha önemli bir epistemik algıya hazlanmaktadırlar.

Tüm bunların çok boyutlu yapısal ve teknik sorunlarla ilgisi aşikardır. Üniversitelerin sayı olarak oldukça hızlı artışı -ki bir zamanlar entelektüelliğin ilk şartı üniversiteyi bitirmekti(Meriç, 1997, s. 21) yeterli ve nitelikli akademik kadro sorunu, kurumsallaşma sorunları, üniversiteye girişteki yapısal aksaklıklar, üniversitelerin altyapı sorunları, beklenti ve öncelik sorunları, öğrencilerin beklentileri, piyasanın talebi, sosyoloji ve sosyal bilimlerin alışılagelmiş kabul, uygulama ve eğilimleri, yıllardır piyasada birikmiş çeşitli nitelik, nicelik ve enstrümanların baskısı, rekabeti ve etkisi, birçok uygulamanın gereksiz yere yol açtığı kirliliği zorlayan ve kıymetlendiren araçların çokluğu, konjonktürel cazibesi, çelişkisi, bulanıklığı gibi sayısız faktörler bunun böyle olmasına bir şekilde katkı vermektedir. Ayrıca son dönemde özellikle sosyoloji sahası dışında, gerçekte kendi alanında da başarılı olamamış, ama bir şekilde sahayı işgal eden ve sığ-negatif katkılarıyla teknisyenliğe soyunan bireylerin artmasını da buna eklemek gerekir. Elbette burada kendini yetiştirmiş istisnaları ayrı tutmakta fayda vardır. 
Bütün bunlarla birlikte biz bu çalışmada özellikle sosyoloji ve kurgucu epistem (imajist modelleme imkanı) üzerinden sosyolojiden faydalanmanın sınırlı tartışmasını konu ederek bu sürece katkı vermeyi hedeflemekteyiz. Buna bağlı olarak da sosyoloji disiplinin zihin inşacı rolünü ve onun imkanlarının nasıl kazanılabileceğine dair bazı belirlenimleri hedeflemekteyiz. $\mathrm{Bu}$ vesileyle de önce sosyolojinin ne olduğunu yeniden kısaca değerlendirerek varmak istediğimiz tespitlere kısa bir altyapı oluşturalım.

\section{2. "Sosyoloji Nedir?" Sorusunun Önemi}

Sosyoloji nedir sorusu tedirgin edici bir sorudur. Üstelik sosyoloji hakkında çok şey bilmek bu tedirginliği daha da çok artırabilir. Çünkü sorunun cevabı; soru sorana, soruyu sorduğu döneme, koşullara, coğrafyaya ve sorunun amacına göre bazı değişiklikler gösterir. Nedeni ne? Bunun da birçok nedeni var: Öncelikle sosyoloji hakkında yalan yanlış çok şey bilinir, sonra sosyoloji gerçekten teknik tarafları olan bir disiplin, ama sanki gündelik bir şeyden bahsedilir gibi bahsedilmesi istenir ondan; ayrıca piyasada sosyolojiyle ilgili de çok kitap var ve bunlar da işin kolayca anlaşılmasını sağlamaktan uzatır.

Önce sosyoloji nedir sorusunun sorana göre değiştiği ifade edilmişti, çünkü sosyoloji hakkında çok fazla önyargı mevcut (Doda, 2005, s. 2). Üstelik bu önyargıların çoğu imgesel olarak sosyolojinin kıyısında dolaşsa da, aslında sosyolojiyi yanlış pazarda ve yanlış tezgahta ve yanlış müşteriye pazarlayan reklamlara benziyor. Bu yanlış anlamaları birkaç örnekle hemencecik deşifre edebiliriz: Toplumda çok yaygın bir biçimde, sosyolojiyle veya kardeş disiplinlerle ilgilenen kişiler hakkında şu kanaatler pek yaygındır: Onlar; çatlak, marjinal, aykırı, kimi ideolojilerin misyoneri, toplumun değerlerine ve inancına pek saygısı olmayan kimseler olarak telakki edilirler. Sosyolojiyi ruh hastalıklarıyla ilgilenen bir bilim olarak düşünen, doğrudan felsefeyle aynı şey olduğunu zanneden, çağdaş yaşamın ajanı olarak kabul eden, anarşist grup ve bireylerin dayanağı olarak gören, yalın manada sorgulayııı bir bilgi faaliyeti olarak algılayan çok çeşitli çevreler de mevcuttur.

Esasen bu yargıları doğrulayan kimi örnekler olsa da bu, tamamen sosyoloji veya benzeri disiplinlerin kendi doğalarından kaynaklanmıyor; daha çok başka sosyolojik sebepleri olan sorunlardan kaynaklanıyor. Kısmen sosyoloji ve benzeri modern bilimlerin kendisi böyle yanılgıların oluşmasına aracı oldularsa da, esasen başka arayışların sosyoloji ve benzeri bilimlerin maskesi altında kolay yuva bulmaları da buna sebep oldu. Tabi bu mesele bile başlı başına uzun sosyolojik bir tartışma konusudur.

İkinci olarak da sosyolojinin ne olduğunun sorulduğu döneme, koşullara ve coğrafyaya (Wilber, 1995, s. 18-19) göre değiştiğini ifade edildi. Zira bu soruyu örneğin 19. Yüzyılın başında Fransa'da sorsaydınız size verilecek cevap ile 21. Yüzyılın başında Türkiye'de sorsaydınız size verilecek cevap farklı olacaktı. Aynı şeyin elbette sosyoloji gibi bir tarafıyla genç ama bir tarafıyla da çok farklı dönem ve tarihlere tanıklık etmiş geniş bir çalışma sahasının neresinden tutarak anlamaya çalıştığımızla ilgili olduğunu da peşinen belirtmeliyim. Ayrıca işin içine, bakış açıları, yaklaşımlar, paradigmalar, ideolojiler, ekoller vb. temel tanımlayıcı farklı öğeler de girince, iş iyice zorlaşıyor.

Kısacası sosyoloji disiplininin belki de cevaplanması en zor sorusu, sosyoloji nedir? Sorusudur! Ama garabete bakın ki doğal olarak ilk akla gelen soru da bu oluyor. Bilinmesi gereken şudur ki bu sorunun cevabı hala tartışılıyor ve yıllardır birçok bilimsel faaliyetin, panelin ve sempozyumun konusu, doğrudan bu soru üzerinden şekilleniyor. Birçok büyük sosyolog da sosyolojik bakış açısını bu soru üzerinde şekillendirmeye devam ediyor. Illk bakışta kendi kendisiyle çok uğraşan can sıkıcı bir disiplin gibi görünebilir sosyoloji. Fakat bunu bir disiplin için acziyet görmek erken bir yargı olurdu. Çünkü bu esasen sosyolojinin uğraştığı sorunlarla da ilgili bir durumdur. Bu nedenle de hem dinamik hem de farkı bakış açılarına 
imkân tanıyan doğasıyla zengin bir disiplinden bahsediyoruz. Yani sosyolojiyle ilgilenmeyi gerçek manada düşünenler bilmelidirler ki sadece yeni bir şeyler öğrenmekle kalmazlar, aslında biraz da sosyolojiyi yeniden yorumlamaya yönelmektedirler. Bu da asılında çok heyecan verici bir şeydir.

Peki, sosyoloji nedir sorusuna hiç cevap bulamayacak mıyız? Elbette, tam aksine çok cevap bulacağız demek istiyorum. O zaman belli oranda da olsa ortak noktalardan ve belli temel kavramlarda da mı bahsedemeyeceğiz? Elbette bahsedebiliriz, çünkü öyle olmasaydı sosyolojiye bir bilim denmesi, yer yer bir tartışma konusu olsa bile, en azından bir disiplin diyemeyecektik. Tabi buna da ilerde değineceğiz. Ama belki de bundan daha önemli olanı, sosyoloji disiplinini belirgin kılan temel unsurun, tüm bu sorulmamıza da manalı cevaplar bulabilme imkanını bize sağlamasıdır. O da "sosyolojik düşünce" sistematiğidir. Esasen biz yukarıda sorduğumuz sorularla, bu bilinci kullanmak ve uygulamasını göstermek istedik. Şimdi sosyolojik düşünce nedir, nasıl gelişmiştir, niçin ihtiyaç hissedilmiştir, önemi ve faydası nedir, bu ve benzeri sorulara kısaca cevap vermeye çalışalım.

\section{Sosyolojik Düşünce ve Düşünce Biçimimize Katkısı}

İnsan zihni evrendeki hiçbir şeyi bağlamsız, özensiz, yorumlanamaz ve kendisi için bir anlam ifade etmez bir biçimde algılamaya yatkın değildir (Öztürk, 2011, s. 72-75). Öyle ki o, bir şekilde kaotik amaçlarla ürettiği şeyleri dahi anlamlı birtakım yorumlara dönüştürmek için birçok mekanizma geliştirmiştir. Esasen böylesi zihinsel düzene koyma motivasyonu olmasaydı bugün bilimlerden ve sanatlardan söz etmemiz de pek mümkün olmayacaktı. Kuşkusuz bilimler bu düzenleme dürtüsünün en profesyonel ve en gelişmiş biçimlerinden birini temsil ederler. "Düşünen bir varlık olarak insan" tarih boyunca "bilmek", anlamak, yorumlamak ve üretmek için çeşitli düşünme dinamikleri geliştirdi. Buna bağlı olarak da düşünmenin çok farklı yolları, biçimleri ve araçlarından söz edebiliriz.

Düşünen kimse her zaman bu yol, biçim ve araçları farkında olarak kullanmaz ise de, bir şekilde düşünmeye konu ettiği şeyin belli kategoriler etrafında aşağı-yukarı tasnif edilebilir bir nitelik arz ettiği iddia edilebilir. İ̧te bilimlerin temel iddiasından birisi de her şeyin mutlaka belli kurallara göre izah edilebilir olmasıdır (Aron, 1994, s. 23-25). Bir bilimi diğer bilimden ayıran şey ise bu izah etme biçimini -kendine özgü ya da değil- konusuna bağlı olarak belli bir yol (metot), belli bir biçim (form), belli araçlar (teknik) üzerinden ama mutlaka sistemli bir biçimde izah edebilme çabasıdır. Sosyolojik düşünce de büyük ölçüde kendine özgü konusu olan ve bu konu/konuları (nesnesini) yine kendine özgü metotlar, formlar ve teknik araçlar üzerinden izah etmeye çalışan sistemli bir düşünme biçimidir.

Elbette ki sosyal bilimler ve özellikle de sosyoloji söz konusu olduğunda bu bilinebilirliğin çok açık ve tamamen ölçülebilir mekanizmalar üzerinden izah edilmesi hiç de kolay değildir. Bu yüzden de sosyolojide birçok metot, biçim ve teknik araçların kullanışılığı tartışılmıştır. Üstelik bu metot biçim ve teknikler, dönemsel ve paradigmasal farklar içermekle birlikte, zamanla gelişmelere de uğramış, yer yer de taban tabana zıt mekanizmalar üzerinden sistematize edilebilmişlerdir.

Peki, eğer çok farklı düşünme biçimleri varsa ve sosyolojik düşünme biçimleri de bir şekilde bu düşünme biçimlerinin bir parçasıysa; bu manada sosyolojik düşünme biçimlerinin ayırt edici özelliklerinden bahsedebilir miyiz?

Bu sorun birçok sosyologca tartışılmış ve çeşitli öneriler getirilmiştir. Öncelikle sosyoloji ve sosyal bilimler söz konusu olduğunda, onun diğer düşünme biçimlerinden tamamen ayrıldığını iddia etmek pek kolay değildir. Üstelik sosyal bilimciler ve özellikle de kurucu sosyologlar Comte, Marx, Durkheim ve Weber (Inal, 2012, s. 37) bu meseleyle özellikle kafa 
yormuşlardır. Bunlar bu bağlamda belirgin ilkeler ortaya koymuş olsalar bile, bu ilkelere uymak kendi açılarından bile pek mümkün olmadı. Yani bu tespitler başı başına bir bilgi konusu olduysa da, uygulamaya ve gerçeği tespite dair açık, koruyucu bir mekanizma geliştiremedi. Fakat buna rağmen bu belirlenimlerinin çok büyük etkileri oldu ve doğrudan değişime katkıları olduğunu da söylemek gerekir. Söylemek istediğim bu teoriler her ne kadar da belirledikleri ilkelerle ulaştıkları sonuçlar arasında birçok çelişkiye yol açtılarsa da, aynı şekilde birçok tartışmaya ve birçok uygulamaya da doğrudan ya da dolaylı olarak katkı verdiler.

Bu yukarıdaki tespite bağlı olarak da çeşitli düşünme mekanizmaları gelişti. Bunlardan birincisi makro teorik yaklaşımlardır. Makro teorik yaklaşımlar, kısaca her şeyi açıklayabilecek ilkeler belirleyerek, toplumsal meseleleri hiçbir bulanıklığa yer bırakmadan bunlarla açıklanabileceği iddiasına dayanmaktadır. Örneğin Marksist sosyolojiye göre her şeyi sınıflar çatışması üzerinden izah etmek doğrudur ve mümkündür. Tarihin yönünü, toplumun şekillenişini, tüm toplumsal kurumları bu postulat (aksiyom: tartışmasız kesin inanca dayalı dayanak noktası) yoluyla açıklamak mümkündür.

Bu teoriyi esas aldığımızda, örneğin Türkiye'deki eğitim sistemindeki tüm tıkanıklıkları gerçekte sınıflar arası çıkar farkından ve çıkar çatışmasından kaynaklandığını iddia edebiliriz. Buna bağlı olarak da bir sınıf kendi lehine ve diğer sınıfın aleyhine güç sahibi olduğu sürece de bu sorunlar düzeltilemez, denebilir. Gerçekte Marks bugün yaşamadığı gibi bugünün Türkiye'sini de görmemiştir. Ancak belirlediği bu ilke takiplerince birçok şeyi açıklayabilecek bir ilke olarak görülmüş ve takipçileri tarafından bugünün Türkiye'sinin sorunlarını anlamamıza da yardımcı olacağı iddia edilmiştir. Bunun gibi birçok makro teori gelişmiş ve bugün yazılan birçok teze ve kitaba -sorunları çözmek üzere- kaynaklık etmişlerdir ve etmeye de devam etmektedir. Elbette bu yaklaşımlar çok eleştirildi. Çünkü sosyal meseleleri açıklamanın bu kadar kolay olmadığı ve bunların da esasen birer dogmatik yaklaşım benzeri yaklaşımlar olduğu iddia edildiyse de, bugün sosyal bilim literatürünü en çok bu yaklaşımlar ya da bu yaklaşımların eleştirisi kaplıyor. Dolaysıyla sosyolojiye yönelecek bir bireyin bu makro teorilere ilgisiz kalması pek mümkün değildir.

Iki sebepten bu makro teoriler önemli; birincisi, bu makro teoriler okuduğunuz sosyoloji veya sosyal bilimler kitaplarının temelini teşkil ediyor. íkincisiyse, birileri bu makro teorilerle hayatı yorumlayıp ona göre adım atıyor. Örneğin 1971 muhtırasını meşrulaştırmak için söylenen ve daha sonra da birçok ironiye konu olmuş -sosyal gelişmişlik, ekonomik gelişmişliği geçmişti-( Başaran, 2016, s. 95) gibi anlamsız görünen bir sözün gerçekte teorinin ne denli manipülatif bir role sahip olduğuna da işaret etmektedir. Bunun sosyoloji teorileriyle alakası nedir? Çünkü Marksist teoriye göre alt yapı üst yapı ayrımı vardır; alt yapı üretim araçlarını temsil eder, yani ekonomik yapıyı. Üst yapıysa siyasi sosyal kurumaları, yani sosyal yapıyı temsil eder. Bu teoriye göre de alt yapı yani ekonomi, üst yapıyı yani toplumsal yapıyı belirler (Doğan, 2013, s. 79). Böyle olunca da darbeciler bu Marksist teoriye göre toplumda sosyal yapının ekonomik yapıdan ileri olduğuna dayalı olarak teoriye aykırı bu gerçeğin büyük sorun olduğunu düşündüler ve bunu da darbe gerekçeleri arasına koydular. Bu yaklaşım esasen birçok şey için geçerli, örneğin bugün birçok kurumda alaturka tuvalet yerine alafranga tuvalet varsa bu bile belli ölçüde modern sosyal teorilere dayanmaktadır. Çünkü modern sosyal teorilere göre toplumlar evrim gereği ilerlerler (Kösemihal, 1995, s. 167) bu da her şeyleri ile ilerlemelerini gerektirir. Bu durumda kültürel öğeler de her yönüyle gelişmiş toplumlarınkine benzer olmalıdır.

Yukarıda görüldüğü gibi sosyal bilimler özellikle de sosyoloji yer yer indirgemeci bir şekilde yorumlanmış ve zaman zaman toplumlara yanlış yön verme konusunda öncü bir rol üstlenmiştir. Ayrıca bunun için de sosyolojik bakış açısı ya da sosyolojik bilince ihtiyacımız var, peki bu nasıl olmalı? Bunu da bir örnekle açıklayalım: Buna verilecek en güzel örneklerden birisi 
de Türkçe ezan hadisesidir. Çok çarpıcı bir örnek olduğu için bu hadiseyi inceleyelim, böylece sosyoloji disiplinin imkânlarıyla indirgemeci karar vermek yerine, sosyolojik okumanın nasıl olacağına dair etkili bir tartışma başlatmış olalım.

Ezanın Türkçeleştirilmesine dair bilinen en yaygın iki yaklaşımı ele alalım. Bunlardan birincisi ezanı Türkçe okutanların ve onların bu yaptığını savunanların iddiası; onlar göre ezan Arapça olduğu için bunu Türkler anlamaz, bunu Türkçeye çevirelim böylece anlaşılır olsun. ikinci yaklaşıma göre ise bu davranış din dışı bir davranıştır ve bunu yapanlar i̇slam'ı tahrif etmeye, bu milleti de dinden soğutmaya çalıştılar. İkisinin de kendice haklı yönleri ve savlarını güçlendiren delilleri vardır. Fakat bu ikisi de doğrudan olaya yönelik bir tavrın sonucudur, sosyolojinin konusudur ancak sosyolojinin tam anlamıyla belirlenimi değildir.

Sosyolojik bakış ise belki şu şekil de olabilir; Cumhuriyet Türkiye'si bakiyesi olduğu Osmanlının batı karşısında her alanda yenilmişliği ve bu yenilmişliğinin her alandaki sebeplerini anlayıp çözümler üretme arzusuna dayanıyordu. Kuşkusuz batının gelişmesinde Batıyı zenginliğe kavuşturan Protestan hareketlerin (Weber, 1997, s. 160) rolü de çok büyüktür. Protestan hareketler de karakter olarak milli idiler ve milli devletlerin oluşmasına da katkı verdiler. Türkiye de bu yolu seçmek zorunda olduğunu düşündü ve sahip olduğu dini, Protestan bir yorumla yeniden ele alma ihtiyacı hissetti. Yani olay ne tam anlamıyla ezanın anlaşılıp anlaşılmaması ne de tam anlamıyla din düşmanlığıydı; açıkçası daha çok batının başarı hikâyesine inanmaktan kaynaklanan bir arayıştı. Çünkü bin yıldır ezanı bu şekilde dinlemiş bir milletin o ezanı anlamaması düşünülemezdi, aynı şekilde mutlak ve süreğen bir düşmanlık olsaydı ezanın tamamen kaldırıması daha uygun olurdu.

Öyleyse biz sosyolojik olarak olayın sosyal sebep ve gelişmelerine ve diğer bağlarına bakarak anlamaya çalışalım. Şayet sosyolojik olarak bir eleştiri yapılacaksa, mesela Protestan hareketleri takip etmenin örneğin Türkiye için geçerli olup olmadığını, ya da batıda Protestan hareketler milli devletleri doğururken bizde milli devletin Protestan İslam yorumunu zorlamasının sosyolojik olarak aynı sonuçları doğurup doğurmayacağını tartışabiliriz. Ya da İslam ile Hıristiyanlı̆ı̆ yapısal olarak çok farklı olmasının aynı tarihsel macerada yorumlanarak siyasal ataklar yapmanın doğru olup olmayacağını da belirleyebiliriz.

Aksi takdirde dindarlık ya da sekülerlik tercihleri üzerinden bir belirlenimde bulunmak, doğrudan sosyolojinin değil ideolojilerin konusudur. Ama görüldüğü gibi sınırları birbirine çok yakındır ve ayırt etmek için özel bir metodolojik hassasiyete sahip olmak gerekmektedir. Çünkü çok tartışılmakla birlikte sosyoloji gibi sosyal bilimler şu veya bu şekilde siyasete, toplumsal kurumlara, çeşitli politikalara ve çeşitli pratiklere doğrudan kaynaklık etmektedir. İşte bu pratiklerin sıradan bir taraftarı olmayı aşacak ama bu yapılara da çeşitli perspektif imkânları doğuracak yer neresidir? Kanaatimce sosyologun görevi burada başlamaktadır.

Bu durumda karşımıza metodolojinin önemi çıkmaktadır. Artistik bir tanımla naçizane ben diyorum ki "metodoloji simya gibidir, sıradan bir bilgiden bilimsel/ilmi bir bilgi elde etmemize yardımcı olur". Simya burada çarpıcı bir metafordur. Üzerine söylenecek çok şey var ama kısaca söylersek, basit madenlerden altın elde etme sanatı olarak bilinir ve asırlarca birçok insansının bu işle uğraştığı bilinmektedir. Böyle bir şey mümkün müdür, bu bizim tartışma konumuz değil ama bu metodoloji için kullandığım anlamıyla mükemmel bir örnek. Gündelik bilgi, malumat, sıradan bir olay bunlar sosyologun bize aktaracağı ya da aktarması beklenen bilgi biçimi değildir.

Elbette tam olarak böyle olmasa da, bazı sosyolojik ekoller bunu da teklif etmişlerdir. Ama daha çok başka bilim dalları bunu yapabilirler, ancak sosyologun rolü farklıdır. İşte tam bu noktada sosyolog bir simyacı gibi sıradan bir olayı incelerken bazı teorik yaklaşımlarla, bağlı olduğu sosyal ve siyasal arka-planlarıyla etkilendiği ve etkilediği gerçeklikler üzerinden kurduğu 
bir koordinat sisteminde o olayın yerini, önemini ve gelişimi tespit etmeye çalışır. O olayı esasen büyük bir kurgunun bir aksesuarı olarak yorumlayacak araçlar geliştirir. Ya da daha önemlisi, kurgulanmış büyük modelleri bu aksesuar sayesinde geçersiz bırakarak kurguyu yeniden bu aksesuar üzerinde şekillendirme becerisine sahip olması gerekmektedir.

\section{Genel Sorunlar ve Yeni Bir Tablo: Sistemlilik Kurgu Becerisi ve Eleştiri İmkânı} Kazanma

Gündelik yaygın ifadesiyle, "sosyolog kahvedeki adam gibi meseleleri tartışamaz", ele alamaz, bir fark olması lazım ama bu fark birkaç artistik lafın arkasına sığınarak da ortaya konamaz. Çünkü zaman zaman kimi popüler sosyologları dinlediğimizde; elinden birkaç artistik kavramı aldığınızda gerçekte geriye sıradan bir tartışma dışında bir şey kalmadığını görürüz. Bu ciddi bir sorundur. Yani illüzyon yaratmadan açık ara disiplinin intiyaçlarına dayalı araçlar üzerinden bağlamlarla yorum yapmayı başarmalıyız.

Bu bağlamda bir örnek inceleyelim: Örneğin internet bağımlılığı hakkında çeşitli yargılar duyabiliriz. Bağımlı olduğu söylenen bir çocuk üzerinden meseleyi kısaca analiz edelim. Ebeveyn, çocuğun duyarsız ve tembel olduğunu söyleyecektir. Öğretmen çocuğun ders çalışmak istemediğini ya da disiplin kazanamadığını ifade edecektir. Buna benzer birçok yorum duyabiliriz. Psikologlar elbette bireyin hikâyesini, ebeveynle olan ilişkisini; özgüven ve uyum sorunları, zeka ve davranışları gibi faktörler üzerinde yoğunlaşarak çeşitli önerilerde bulunacaktır.

İşe sosyolog, tüm bu koşulları ve bireyin bu koşullarda yeniden posizyon alması üzerinden makro analizler yaparak işini yapmış olacaktır. Değişen toplumsal şartları, bu çocuğun yaşadığı ve sıkıştığı daire (bina) kültüründen çekirdek ailede bireyin sosyal ağlarının daralmasına, sosyalleşme imkânlarının teknolojik gerçeklikler üzerinden pazarlanmasının bireyin yalnızlaşması ve yabancılaşmasını getirdiği, teknolojik ağların bireysel güvene ve çok yönlü bedel ödemeye sınır çektiğini ve bu gibi sorunları tespit edecektir.

Tabi bu yaklaşımı eleştirenler de var; makro teorilere karşı çıkarak toplumun belli çerçeveler içinde değerlendirilemeyeceğini söyleyenler olduğu gibi, her hadisenin kendi gerçeği içinde değerlendirmesi gerektiğini söyleyenler de var. Tabii toplumsal gerçeklikleri ölçerek nicelikleri üzerinden anlamamız gerektiğini söyleyen uygulama ağarlıklı tekno-sosyoloji yaklaşımları da var. Bunlarının hepsinin de geniş etki alanlarına sahip olduğunu peşinen söylemeliyim. Tüm bunlarla ne demek istiyorum; bunun için sosyolojik düşüncenin kökenleri, gelişimi, tarihsel çerçevesinin nasıl oluştuğuna ve sosyolojik düşüncenin araçlarının neler olduğuna bilmek yetmez; onları metodik bir üreteci faktöre dönüştürebilmek gerekmektedir. Belki sonra yeni modelleri gerçeğin canlılığına göre yeniden kurabiliriz.

Bu bağlamda önümüze anlaşılabilir, disiplinin farkını yansıtacak, kullanışı modeller konması zarureti vardır. Bu çerçevede öncelikle bir disiplinin teorik postulatları, bunu garantiye alan metodik çatısı, gerçeği yoruma konu eden uygulama teknikleri ve de faydaya dönüştürecek farbrik bir sahadan bahsetmek mümkündür.

Öncelikle teori ve teorizasyon sorunu eğitim-öğretim faaliyetlerimizin en zayıf noktasını teşkil etmektedir. Bu yargı kuşkusuz teorik bilgiyle muhatap olmamızla ilgili bir durum değildir, onu anlamak ve işlevlendirmekle ilgili bir durumdur. Birçok göstergeyi paranteze almak kaydıyla kestirmeden ifade etmek gerekirse teori bir malumat alanı olarak algılanmaktadır. Oysaki teori bir malumat değil; verileri, yorumları ve bilgileri bilgisayar diliyle ifade etmek gerekirse, üzerinde işlem yapacağınız programlara benzemektedir. İşte herhangi bir öğrencimize bunu ifade etmekte güçlüklerimiz var. 
Hangi bilgi faaliyetli içinde olursak olalım sosyal bilimlerde onu kimi teori ve paradigmalar üzerinden yorumluyor, kıymetlendiriyor ve modelliyoruz. Bunun doğruluğu, ahlakiliği gerçekliği yansıtması gibi uzun uzadıya tartışıması gereken boyutları vardır. Ama bu başka bir çalışmanın konusudur. Bununla birlikte şu veya bu şekilde bunun böyle olduğu neredeyse kaçınılmaz bir süreç olarak açığa çıkmaktadır.

Birincisi öğrenci karşılaştığı yargı ve modelin ya da yorumun kaynaklandığı teorik kabullerin bağını kuramıyor/ ya da bunun böyle olduğunu göremiyor. Esasen metaforik ifadeyle vitrin mutfak/atölye-tarif/tasarım ilişkisini kurma gereği duymuyor. Yani teori mekanizasyonunu anlamakta güçlük çekiyor. Biz teorileri öğretirken teori mekanizasyonu kavratmayı ıskalayabiliyoruz, denesek de yeterince başarılı olamayabiliyoruz. Yani teorinin belli ilke ve araçlara göre yapabilecek, üstelik herkesçe yapılabileceğinin sistem, yöntem, araç ve mekanizasyonu önceleme ve cüret etme sorunu büyük bir sorundur. Esasen batı dışı toplumların bu dogmatik sorunu artık aşması gerekmektedir.

Ikinci olarak ise bu teorilerin yaslandığı tarladan mutfağa, hammaddeden atölyeye veri tabanı üzerine kurulduğu dinamik sosyolojik ve medeniyet havuzunun önemini ve zorunluluğunun görülmesi sorunudur. Bu manada öğrenci teorileri gökten düşen ayine sabiteler olarak anlamakta ya da onlara genellikle öyle öğretilmektedir.

Üçüncü olarak ise, teorilerin belli akıllarca ve belli sorunsallaştırmalara dayalı ve belli çıkar tazyiklerinin bir sonucu olarak forme olduğu sistematiğinin sahici olarak yansıtılması sorunudur. Tüm teorilerin şu veya bu şekilde kimi ihtiyaç ve o ihtiyacı önceleyen akılların çıkar ve eğilimlerine yaslandığını kazandırma sorunuyla karşı karşıyayız.

Bununla birlikte çok ihtiyaç hissettiğimiz yeni bir dalga başlayacaksa teori ve torizasyon teori kurguculuğu bazı özel durumları da kısaca dillendirmekte fayda var. Bunlar da özetle teoriciliğin ahlakiliği, medeniyet uyumu ve de dogma olmasını engellemek uyarısıdır. Başka bir çalışmanın konusu olarak esnek-teori geleneğini oluşturma gereksinimi doğmaktadır.

Önemli bir sorun olarak da metot ve gerçeklik temasını bir sistematik içinde değerlendirme sorununa değinmek gerekmektedir. İşte burada metodik simyacılık devreye girmekte, dağınık ya da zihne konu olmamış ham hali yaklaşım, teori, sorun ve sınırlama ilişkisi içinde kıymetlendirme becerisi gündeme gelmektedir. Böylece öğrenci gördüğü her olay ve nesneye sistemli sorular sorarak onu birçok boyutuyla disiplinin konusu yapmaya başarabilecektir.

Üçüncü önemli bir sorun olarak da, çalışma, yorumlama, teori ve metoda bağlı olarak bir sonuca vardığında ona çeşitli modellere bağlama ve kullanıma dayalı olarak fabrikleştirme yani kullanışlı çıktılara bağlayacak mekanizasyon geliştirebilme imkânına kavuşturma sorunudur. Kısacası ürünleştirme sorunudur.

Fen bilimlerinden bir örnek verecek olur ise, kuantum fiziği, seçeneklere dayalı gerçeklik okumaları; saha teması ve de ürün olarak da birçok çıktı imkânından birisi olan plazma tv gibi bir hiyerarşiden bahsedebiliriz. Sosyal bilimlerde teorize etme ve teori teklifi, ona bağlı metot ve araçlara saha ve gerçekli yorumu ve fabrikleşmiş çıktılar sistematiği şeklinde gerçekleşecektir. Bu zaten bir şekilde olmaktadır ama kaotik ve bağlamsız gibi görünen bu durumları eğitim-öğretim süreçlerinde çok açık sistemli bir bütün olarak kazandırmayı hedefleyecek bir program modellemesi geliştirmemiz gerekmektedir. Buna bağı olarak da örneğin anabilim dalları, teori, teorisazyon ve metodoloji; saha, sorun ve gerçeklik; fabrikleştirim, ahlakilik ve ürün şeklinde yeniden forme edilebilir (Öztürk, 2015, s. 5-10). Elbette bu sadece bir tekliftir, buradaki amaç daha çok bu sistematiğin bir bütün olarak eğitimöğretim süreçlerinde etkin ve açık hale getirilmesi çabasıdır. 
Peki, bunun faydası ne olacaktır? Öncelikle öğrenci sosyoloji disiplinini sıradan bir malumat alanı olarak değil bir perspektif sahası ve bir bilgi üretme teknolojisi olarak kullanmayı öğrenecektir. Buna bağlı olarak da medeniyet ve toplumun ihtiyaç ve eğilimleri esasına dayalı olarak sosyal bilim yapma imkânı doğmuş olacaktır. Değişimler, ihtiyaçlar, dönemler, koşullar vb. faktörlere bağlı olarak sosyolojinin imkânı daha da etkin hale gelmiş olacaktır. Böylece sadece transfere bağlı ve yabancılaştırıcı bilim anlayışından, göreli-gerçeği yorumlama sistematiği kazandıran işlevli ve katkı verici bilim anlayışına da geçmiş olacaktır. Aynı zamanda bu muhatap olduğu cari bilgiyi de gerçek değeriyle anlamasına da katkı verecektir.

\section{SONUÇ, TARTIŞMA VE ÖNERILER}

Sosyoloji ve Sosyal Bilimler malumatfuruş ve kaotik bir bilgi faaliyeti olma riskiyle karşı karşıyadır. Ya indirgemeci teoriler ya imajinatif, sansasyonel kodlar, ya da katı, manasız, çoğaltıcı teknik bilgi alanı olarak belirsiz, çelişkili ve yer yer de işlevsiz bir rol üstelenmektedirler. Elbette üniversitelerin hem sayı olarak hem de öğrenci sayısı olarak gittikçe artığı bir ortamda bu sorunlar geri planda kalmaktadır. Ancak disiplinlerin rol ve işlevleri onların sahici olarak var olmaları ve ilerde de bu rollerini sürdürebilmeleri açısından önemlidir.

Bu bağlamda sosyolojinin hem mahiyet hem de teknolojik olarak rol ve işlevini sürdürmesi için, indirgemeci malumatlar ile yatay teknik aparatlar ve de sansasyonel çıkışlara sebep olmaktan daha fazla imkanları vardır. Bu imkânları sistemli olarak yeniden tasnif etmekte fayda vardır.

$\mathrm{Bu}$ çerçevede teori kurguculuğu ve teori mekanisazyonunun anlaşılması, köken ve işlevlerinin okunabilmesi önemlidir. Ayrıca ihtiyaç duyulduğunda alternatif mekanizasyonların kolayca geliştirilebildiği özgüven, bilgi ve becerinin desteklenmesi gerekmektedir. Buna bağlı olarak gerçeklerle, nesneyle ve olay ile tamasın metodolojik bir perspektife yükseltilmesi ve bu bağlamın işlevli hale getirilerek sıradan bilgiden özel bilgi üretme imkânı zorlanmalıdır. Tüm bunlara bağlı olarak da bilgiyle olan temasın bir çıktıya; ürüne ve faydaya bağlanacak kanalların sisteme bağlanması zarureti vardır. Elbette bunları gerçekleştirirken, belli ahlaki kaygılar, medeniyetin imkânları ve insanlığın ihtiyaçları göz önünde bulunduracak insanileştirilmiş bir hassasiyet zaruret kesp etmektedir.

\section{KAYNAKLAR}

Aron, R. (1994). Sosyolojik düşüncenin evreleri. (Çev: Korkmaz Alemdar) Ankara: Bilgi Yayınevi.

Barnes, B. (1995). Bilimsel bilginin sosyolojisi. Ankara: Vadi Yayınları.

Başaran, D. (2016). 12 Mart Askeri Muhtırası ve Türk Demokrasisi. Betül K. Yerdelen vd. (Ed.) Demokrasi: Darbeler ve Tepkiler. Ankara: Divan.

Doda, Z. (2005). Introduction to sociology. EPHTI.

Doğan, M. (2013). Hiperprestij grupları. İstanbul: Neva Yayınları.

İnal, K. (2012). Geleceğin eğitim sosyolojisi. Eğitim sosyolojisi. (Ed. İsmail Doğan). Ankara: Nobel Yayınları.

Kösemihal, N. Ş. (1995). Sosyoloji tarihi. İstanbul: Remzi Kitapevi.

Meriç, C. (1997). Mağaradakiler. İstanbul: İletişim Yayınları.

Öztürk, A. (2015). Medeniyet ve sosyoloji. Ankara: Elis Yayınları. 
Öztürk, A. (2011). Kriz sosyolojisi. İstanbul: Doğukitapevi.

Weber, M. (1997). Protestan ahlakı ve kapitalizmin ruhu. Ankara: Ayraç Yayınları.

Wilber, K. (1995). Transandantal sosyoloji. İstanbul: İnsan Yayınları.

Yıldırım, E. (2007). Bilginin sosyolojisi. Bursa Ekin: Yayınları. 


\section{SUMMARY}

One of the main roles of sociology is to be able to see and be able to formulate what you see. But sociology departments have some problems in this issue. In general, the main problems in this title in sociology education can be expressed as follows: It is a serious dilemma that students cannot understand problems and concepts first and foremost by linking concepts and realities to their own origins. Sociological terms, methods and approaches do not make enough changes in the minds of students. If there is a change it could be only at a symbolic level. Students generally regard either dictated mythic facts or popular idols problems.

Moreover, the fact that the students or the academicians take the facts depend on the other motivations rather than the needs of the discipline principles. For example, this situation is shaped by the needs of the community or ghetto, where the student is a member. Of course, these problems do not depend solely on the relationship of discipline to the student. Sociology as a discipline has its own ontological problems.

It is remarkable that the methodological leadership presented in the teaching of sociology and social sciences depicts a multi-parted and irreconcilable story. Reduced theories, such as popular, speculative and sensational judicial oppression, chaotic imaginative intensities and technician activity, are also a time when this process is thoroughly blurred. Accordingly, students are far from being able to see and develop sophisticated ontologies of sociological terms, concepts, approaches, methods and techniques that they learn or are familiar with, using them as a point of action, or testing their own mismatches themselves.

The second fundamental problem is the inability to have the power of interpretation. Students do not consider using theories, methods and techniques they see them as instruments of interpretation. They interpret new situations or a parallel phenomenon, because they have not been working, with interpretations of sociology, with far-reaching performance, and more often with reflections of daily life.As a matter of fact, students also misunderstood the question of comment. As it is known, there are many dimensions of interpretation. In the simplest sense, interpretation refers to how a field depends on a method, approaches, theories, and how it evaluates it, based on adequate material and technical knowledge, by establishing a link between the field and the subject.

Thirdly, by modeling a problem, they are unable to connect the sighting or problematizing to a coherent system, a mature game rule. What they can do does not go beyond a bright display of the game. All of these are obviously concerned with multidimensional structural and technical problems.Sociology and Social Sciences have opposed to the risk of being an ordinary knowledge and chaotic information activity. Many times they play an uncertain, contradictory, and somewhere dysfunctional role as the domain of reductionist theories, imaginative, sensational codes, solid, ineffective, multiplicative technical knowledge. Of course, these problems go back to the planet in an environment where the number of universities are rapidly increasing.

However, the roles and functions of the disciplines are crucial in their existence as genuine and in the future to be able to sustain these roles. In this framework, it is important that the theory builder and the theory mechanics be understood, their origins and their functions readable. In addition, when needed, it is necessary to support self-confidence, knowledge and skill in which alternative mechanizations can be easily developed. Accordingly, it is necessary to raise the methodological perspective of facts, objects, and events, and to make this context functional so that ordinary knowledge can produce special knowledge. Methodology is like alchemy. Thanks to it we obtain superior information from ordinary knowledge. Depending on all these, the contact with the information comes out; It is necessary to connect the channels to the product and the benefit to the system. Certainly, while doing these things, certain moral concerns, the possibilities of civilization, and humanized sensitivity to consider the needs of mankind desperate. 